\title{
Germination and seedling growth of corn (Zea mays l.) under varying levels of copper and zinc
}

\author{
${ }^{1}$ S. Mahmood, ${ }^{2}$ A. Hussain, ${ }^{1}$ Z. Saeed and ${ }^{3}$ M. Athar \\ ${ }^{1}$ Institute of Pure and Applied Biology, Bahauddin Zakariya University, Multan, Pakistan \\ ${ }^{2}$ Department of Botany, Government College for Women, Vehari, Pakistan \\ ${ }^{3}$ California Department of Food and Agriculture, 1220 N Street, Sacramento, CA 95814, USA \\ Received 22 July 2005; \\ revised 5 August 2005; \\ accepted 29 August 2005; \\ available onlined 30 September
}

\begin{abstract}
The heavy metal tolerance in corn (Zea mays L.) var. 'Neelum' was assessed at germination and seedling growth after having subjected it to different concentrations of $\mathrm{CuSO}_{4}$ and $\mathrm{ZnSO}_{4}$. Germination was not affected by any of the metal tested, whereas initial growth was strongly inhibited by increasing concentrations of $\mathrm{ZnSO}_{4}$. Seedlings developed toxicity symptoms in the presence of both metals but more chlorotic and necrotic regions were observed at varying levels of $\mathrm{ZnSO}_{4}$ than $\mathrm{CuSO}_{4}$. The metal accumulation was concentration dependent. Z. mays seedlings accumulated more copper in roots but greater contents of zinc in their shoots. On the basis of results presented here, it can be concluded that the cultivar of the species tested has shown a marked sensitivity to the presence of small amounts of metals present in the growth medium. The data support the assumption that metal sensitivity is probably due to strong tendency of the species to accumulate them. This justifies that the corn variety 'Neelum' is not suitable for the cultivation under situations where water and soil suffer from occasional and/ or transitory metal pollution.
\end{abstract}

Key words: Corn, heavy metals, copper, zinc, germination, seedling growth

*Corresponding Author, E-mail: atariq@cdfa.ca.gov

\section{Introduction}

Unrestricted mining, municipal waste disposal practices and extensive use of agrochemicals have resulted in the addition of large amounts of heavy metals at many places of the world (Ernst 1996, Mullar et al. 2000). These metals persist indefinitely in soil thereby posing an ever-increasing threat to human health and agriculture (Leyval et al. 1995). Metal toxicity primarily depends on plant species as they exhibit considerable genetic variation in their ability in tolerating amounts and the concentration of specific heavy metals (Vojtechova and Leblova 1991). Some heavy metals are essential micronutrients for plants but their excess may result in metabolic disorders and growth inhibition in most of the plant species (Claire et al, 1991). The apparent damage of plant tissues due to excessive amount of heavy metals in the growth medium can be used as an indicative of toxic effects of metals (Mullar et al. 2000). Corn ranks third in the global cereal production and is utilized as food, feed and fodder. Large quantities of corn are used in extracting oil, manufacturing cellulose products, and mild abrasives. There are studies about the response of crop species to heavy metals reporting mechanisms that are responsible for their tolerance or sensitivity (Chatterjee and Chatterjee 2000, Ernst
1996, Lindon and Henriques 1992, Mullar et al. 2000). Avoidance of metal uptake or its accumulation in plant tissues without developing any toxicity symptoms is considered as metal tolerance in plants. Sensitive species may lack this mechanism and show toxicity symptoms and poor development. The present study was aimed at determining heavy metal tolerance in corn and to draw parallels between tolerance and metal accumulations. Heavy metal tolerance was tested at germination and seedling growth of corn as these are the key events for the establishment of plants under any prevailing environment (Welbaum et al. 1998).

\section{Materials and Methods}

Seed of corn (Zea mays L. var. Neelum) was obtained from ICI Pakistan Ltd, Multan. The germination of the seeds was more than $98 \%$. Seeds were surface sterilized in 5\% sodium hypochlorite solution for 10 minutes before use, to avoid fungal contamination. Seeds were then washed thoroughly with deionized water. $\mathrm{CuSO}_{4}$ and $\mathrm{ZnSO}_{4}$ solutions were prepared containing one thousand ppm of $\mathrm{Cu}^{+2}$ and $\mathrm{Zn}^{+2}$. Different concentrations (3, 6, 9, $12 \mathrm{ppm}$ ) of both metals were prepared by further dilution of the $1000 \mathrm{ppm}$ solutions. 
Thirty petri dishes $(8 \mathrm{~cm}$ diam) were washed with deionized water and lined with filter paper (Whatman No. 1) for germination study. Each petri dish received 20 seeds of corn variety Neelum and 20 $\mathrm{mL}$ of treatment solution. Treatments comprised of control (deionized water), 3, 6, 9, and $12 \mathrm{ppm}$ of $\mathrm{Cu}^{+2}$ and $\mathrm{Zn}^{+2}$. The petri dishes were arranged in a completely randomized block design with three replicates of each metal treatment. The experiment was conducted in a growth chamber at $25^{\circ} \mathrm{C}, 12$ hours light /12 hours dark period, (illumination of 2500 lux, Philips T2 40W/33 lamp). The seeds were observed for germination each day and recorded. Seeds were considered germinated when both radicle and plumule had emerged to about $0.2 \mathrm{~cm}$.

For seedling experiment, 20 pre-germinated seeds were transferred to 30 plastic beakers filled with $100 \mathrm{~mL}$ of $\mathrm{Cu}^{+2}$ and $\mathrm{Zn}^{+2}$ solutions of different concentrations as used for germination experiment. An equal quantity of polystyrine beads was added to each beaker. This experiment was arranged in a complete randomized block design and each block contained three replicates for each metal concentration. The beakers were aerated during the course of seedling development. Seedlings were allowed to grow for 12 days then they were taken out from the solutions and washed carefully. The measurements were made for root and shoot length. Necrotic and chlorotic regions were observed using Swift Stereomicroscope with an eyepiece graticule of $10 x$ magnitude.

Metal contents were determined after rinsing of seedlings for five minutes under a permanent flow of deionized water and then dried at $110^{\circ} \mathrm{C}$ for 24 hours. Samples were ashed by heating at $600^{\circ} \mathrm{C}$ for six hours and digested in $\mathrm{HCl}$. The concentration of metal in the seedling was measured by atomic absorption spectroscopy (Varian AAS, 1475). It was expressed in ppm on the basis of fresh weight using the following formula,

$$
\text { p p m (1) }=\frac{\operatorname{ppm}(\text { d) } x \text { d.w. }}{\text { f.w. }}
$$

where, d.w. = Dry weight and f.w. $=$ Fresh weight The biological absorption coefficient (BAC) for the fresh weight was determined with the formula,

$\mathrm{BAC}=\frac{\mathrm{ppm}(\text { fresh })}{\operatorname{ppm}(\mathrm{sol})}$

$\operatorname{ppm}($ sol $)=$ Concentration of the metal in the original solution.
Data were subjected to a two-way analysis of variance in order to elucidate differences between two metals and treatment levels.

\section{Results}

Germination of Z. mays seed was not affected by any of the solutions tested. Similarly, the rate of germination was constant both in the absence and presence of these metals (Table 1). Germination started on the fourth day and was completed by seventh day after placing seeds in the petri dishes. Root and shoot lengths of 12 days old seedlings at varying concentrations of $\mathrm{Cu}^{+2}$ and $\mathrm{Zn}^{+2}$ are presented in Table 1 . The longest roots were observed at control for both the metals. The shortest roots were observed at $12 \mathrm{ppm}$ of $\mathrm{CuSO}_{4}$. There was a marked difference $(\mathrm{P}<0.00)$ in root length at varying concentrations of $\mathrm{CuSO}_{4}$. The extent of decline was significantly greater for $\mathrm{Cu}^{+2}$ than for $\mathrm{Zn}^{+2}$. The root length was not much influenced by varying concentrations of $\mathrm{ZnSO}_{4}$ (Table 1). Analysis of variance indicated a significant $(\mathrm{P}<0.001)$ differential effect of both salts on the development of root. Similarly, varying concentrations of metals had a significant $(\mathrm{P}<0.01)$ adverse effect on root length (Table 3).

The two metals $(\mathrm{P}<0.05)$ and their varying s $(\mathrm{P}<$ 0.001 ) had a significant effect on shoot development (Table 3). The shortest shoot length was observed at the highest salt concentration (12 ppm) of $\mathrm{ZnSO}_{4}$. However, longer shoots of $Z$. mays were recorded under $\mathrm{CuSO}_{4}$ (Table 1). A considerable $(\mathrm{P}<0.001)$ effect of both metals on shoot/root ratio is evident (Table 3). This ratio was greater for varying concentrations of $\mathrm{CuSO}_{4}$ while smaller ratios were observed at different concentrations of $\mathrm{ZnSO}_{4}$ (Table 1). The effects of copper and zinc on seedling health were observed after the $12^{\text {th. }}$ day of growth by stereoscopic microscope (Table 1). The increasing concentrations of both metals had caused a significant $(\mathrm{P}<0.001)$ damage to seedling health (Table 3). Although more necrotic region on the seedlings of $\mathrm{Z}$. mays seedlings was observed in the presence of $\mathrm{ZnSO}_{4}$ than $\mathrm{CuSO}_{4}$ but the difference was non-significant (Table 3). The development of chlorotic region was observed in the presence of both the metals, which significant $(\mathrm{P}<0.001)$ influence on the growth of the seedlings (Table 3). Under varying concentrations of $\mathrm{ZnSO}_{4}$, considerably greater chlorotic region was developed as compared to $\mathrm{CuSO}_{4}$ (Table 1). The higher 
concentrations of both the metals caused significant ( $\mathrm{P}<0.001)$ seedling damage (Table 3 ).

The metal content of the shoot of $Z$. mays grown in the presence of $3,6,9$, and $12 \mathrm{ppm} \mathrm{Cu}^{+2}$ was $0.27,0.30,0.27$, and $0.37 \mathrm{ppm}$ of fresh weight, respectively. The BAC was $0.48,0.27,0.08$ and 0.066 (Table 2) and \% absorption was 10, 20, 56.7 and 75 (Fig. 1) for each of the respective concentrations. In the presence of different concentrations of $\mathrm{Cu}^{+2}$, roots accumulated 0.41 , $0.43,0.49$ and 0.60 metal content at 3, 6, 9,and 12 ppm respectively; and the BAC observed was 0.13 ,
0.081, 0.047 and 0.05 for above concentrations respectively (Table 2). Maximum $\mathrm{Cu}^{+2}$ absorption was observed in shoot at $12 \mathrm{ppm}$ (Fig. 1).

In the presence of different concentrations of $\mathrm{Zn}^{+2}$, roots accumulated 0.24 and $0.22 \mathrm{ppm}$ of $\mathrm{Zn}^{+2}$, at 3 and $12 \mathrm{ppm}$ that was highest at $6 \mathrm{ppm}(0.42)$. The BAC observed was 0.09 and 0.018 for these concentrations respectively. The percent absorption in shoot was the highest at $12 \mathrm{ppm}$ (Fig. 1). For the seedlings of $Z$. mays grown in the presence of 3,6 , 9 and $12 \mathrm{ppm}$ of $\mathrm{Zn}^{+2}$, the metal contents of the shoot were $0.29,0.51,0.44$ and 0.40 respectively.

Table 1: Overall mean values ( \pm S.E.) for various traits of Zea mays seedlings grown under different concentrations of copper and zinc

\begin{tabular}{|lccccc|}
\hline \multicolumn{5}{c|}{$\mathrm{Cu}^{+2}$} \\
& \multicolumn{5}{c|}{ Metals concentration (ppm) } \\
Germination (\%) & Control & 3 & 6 & 9 & 12 \\
Root length (cm) & $99.5 \pm 0$ & $97.9 \pm 0.056$ & $98.2 \pm 0.052$ & $97.5 \pm 0.067$ & $97.6 \pm 0.093$ \\
Shoot length (cm) & $3.49 \pm 0.11$ & $3.39 \pm 0.17$ & $3.15 \pm 0.06$ & $2.22 \pm 0.13$ & $1.25 \pm 0.12$ \\
Shoot/root ratio & $6.28 \pm 0.01$ & $6.07 \pm 0.24$ & $5.35 \pm 0.15$ & $5.23 \pm 0.17$ & $4.25 \pm 0.16$ \\
Necrotic region (mm) & $1.79 \pm 0.04$ & $1.79 \pm 0.12$ & $1.69 \pm 0.18$ & $2.35 \pm 0.25$ & $3.4 \pm 0.14$ \\
Chlorotic region (mm) & $0.1 \pm 0.001$ & $1.5 \pm 0.006$ & $2.5 \pm 0.007$ & $6.9 \pm 0.05$ & $8.3 \pm 0.06$ \\
& $0.1 \pm 0.001$ & $1.0 \pm 0.016$ & $2.3 \pm 0.011$ & $2.5 \pm 0.017$ & $2.8 \pm 0.016$ \\
Germination (\%) & & $\mathrm{Zn}{ }^{+2}$ & & & $97.5 \pm 0.026$ \\
Root length (cm) & $99.5 \pm 0$ & $98.3 \pm 0.08$ & $98.7 \pm 0.018$ & $98.1 \pm 0.085$ & $2.45 \pm 0.11$ \\
Shoot length (cm) & $3.55 \pm 0.16$ & $3.51 \pm 0.11$ & $3.24 \pm 0.03$ & $3.15 \pm 0.05$ & $2.19 \pm 0.06$ \\
Shoot/root ratio & $6.25 \pm 0.02$ & $4.26 \pm 0.11$ & $3.34 \pm 0.08$ & $3.02 \pm 0.02$ & $0.72 \pm 0.12$ \\
Necrotic region (mm) & $1.76 \pm 0.11$ & $1.21 \pm 0.16$ & $1.03 \pm 0.15$ & $0.95 \pm 0.01$ & $15.3 \pm 0.008$ \\
Chlorotic region (mm) & $0.2 \pm 0.0025$ & $2.0 \pm 0.001$ & $12.3 \pm 0.005$ & $14.5 \pm 0.009$ & $12.3 \pm 0.012$ \\
\hline
\end{tabular}

Table 2: Metals content of Zea mays seedlings grown under different concentrations of copper and zinc

\begin{tabular}{|lccccccccc|}
\hline & $\mathrm{Cu}^{+2}$ & \multicolumn{7}{c|}{$\mathrm{Zn}^{+2}$} \\
\hline & \multicolumn{7}{c}{ Metals concentration (ppm) } \\
Root & 3 & 6 & 9 & 12 & 3 & 6 & 9 & 12 \\
Metal content (fresh weight) ppm & 0.41 & 0.43 & 0.49 & 0.60 & 0.24 & 0.42 & 0.18 & 0.22 \\
Biological absorption coefficient & 0.13 & 0.081 & 0.047 & 0.05 & 0.09 & 0.085 & 0.02 & 0.018 \\
Shoot & & & & & & & & \\
Metal content (fresh weight) ppm & 0.27 & 0.30 & 0.27 & 0.37 & 0.29 & 0.51 & 0.44 & 0.40 \\
Biological absorption coefficient & 0.48 & 0.27 & 0.08 & 0.066 & 0.08 & 0.046 & 0.048 & 0.04 \\
\hline
\end{tabular}

Table 3: Analysis of variance (mean squares) for various growth attributes of Zea mays seedlings grown under different concentrations of copper and zinc

\begin{tabular}{|lcccccc|}
\hline Characters & MS Metal & Significance & MS $_{\text {Conc. }}$ & Significance & MS $_{\text {Inter }}$ & Significance \\
\hline Germination (\%) & 248.90 & N.S. & 39.10 & N.S. & 142.07 & N.S. \\
Root length $(\mathrm{cm})$ & 21.98 & $* * *$ & 1.07 & $* *$ & 4.10 & $* * *$ \\
Shoot length (cm) & 4.74 & $*$ & 9.67 & $* * *$ & 1.19 & N.S. \\
Shoot/root ratio & 12.36 & $* * *$ & 0.78 & N.S. & 0.65 & N.S. \\
Necrotic region (mm) & 0.78 & N.S. & 2.05 & $* * *$ & 0.53 & N.S. \\
Chlorotic region (mm) & 4.25 & $* * *$ & 1.09 & $* * *$ & 4.25 & $* * *$ \\
\hline
\end{tabular}

$*, * *, * * *$ denote significance at $\mathrm{P}<0.05, \mathrm{P}<0.01$ and $\mathrm{P}<0.001$ respectively, N.S. $=$ non significant

$\mathrm{MS}_{\text {Metal }}=$ Mean square metal, MS ${ }_{\text {Conc. }}=$ Mean square metal concentration, MS $_{\text {Inter }}=$ Mean square interaction 

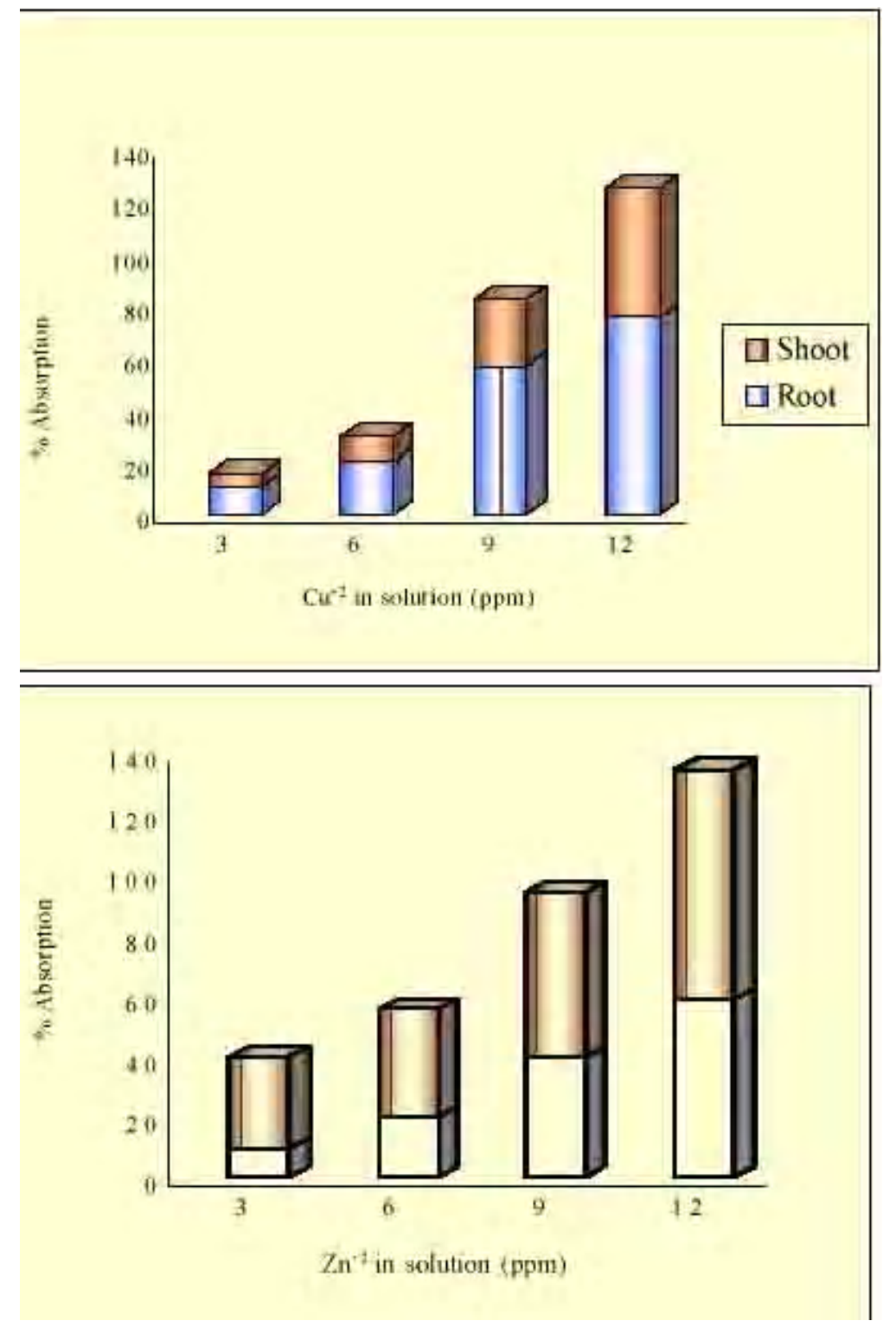

Fig. 1: Percent absorption of Zea mays seedlings grown under different concentrations of copper and zinc

The BAC was $0.08,0.046,0.048$ and 0.04 for each of these respective concentrations (Table 2) and the $\%$ absorption being 30, 36, 55 and 76 (Fig. 1).

\section{Discussion and Conclusions}

The present results showed that the germination of $Z$. mays seeds was not influenced by the presence of $\mathrm{Cu}^{+2}$ and $\mathrm{Zn}^{+2}$ in the culture medium. The toxicity difference of the two metals was not evident at seed germination. The results of seed germination clearly indicated that the increasing concentrations of these two metals did not influence the germination. The insignificant effect of metal toxicity on germination suggests that seed uses its own reserves during germination process and this process is not influenced by the presence of metal ions in the culture medium
(Stefani et al. 1991). Therefore, the presence of small concentration of heavy metals in the culture medium cannot account for inhibition of germination in Z. mays. These results are consistent with other herbaceous species like Triticum vulgare and Avena sativa (Fiussello, 1973) and in arboreal gymnosperms Piceae rubens, and Abies balsamica (Scherbatskoy et al. 1987). The presence of heavy metals in the culture medium had a significant adverse effect on seedling growth and health. The study showed reduction in root and shoot length, and development of chlorotic and necrotic area. The highest concentration of $\mathrm{Zn}^{+2}$ prevented the shoot growth. The growth of root was arrested in the presence of $12 \mathrm{ppm}$ of $\mathrm{CuSO}_{4}$. The presence of $\mathrm{Cu}^{+2}$ and $\mathrm{Zn}^{+2}$ affected the growth of $\mathrm{Z}$. mays 
seedlings; the reduction in shoot growth was directly related to the heavy metal concentration (Table 1). Walley et al. (1974) reported similar effects in a number of other plant species.

The presence of $\mathrm{Cu}^{+2}$ in the culture medium showed a stronger effect on root growth than shoot while the reverse was true for $\mathrm{Zn}^{+2}$ This suggests some preventive mechanism for the reduced translocation of $\mathrm{Cu}^{+2}$ from root to shoot (Nishizono et al. 1989). The distribution of the two metals was different between root and shoot as shown in Table 2. $\mathrm{Cu}^{+2}$ seem to concentrate in the roots while $\mathrm{Zn}^{+2}$ appeared to be more diffusible than $\mathrm{Cu}^{+2}$. Stefani et al. (1991) similar pattern of distribution of heavy metals in Juncus acutus seedlings.

All the concentrations of $\mathrm{Zn}^{+2}$ and $\mathrm{Cu}^{+2}$ caused the necrosis of shoot. However, actual toxicity of any of these metals was not ascertained. Nevertheless, the development of necrotic region depended on concentration. These findings agree with the observations of Chatterjee and Chatterjee (2000), who reported similar effects of cobalt, chromium and copper on cauliflower. The chlorosis caused by the presence $\mathrm{Cu}^{+2}$ was in a minor extent as compared to $\mathrm{Zn}^{+2}$. This may be explained by variable action of these metals on chloroplast. These assumptions are supported by independent studies by Becerril et al. (1988) and Barcelo et al. (1988).

The accumulation of metals in roots and shoots varied greatly. The amount of $\mathrm{Cu}^{+2}$ accumulated increased with its availability in the medium. However, the extent of $\mathrm{Zn}^{+2}$ deposition was the maximum at $6 \mathrm{ppm}$. Therefore, $\mathrm{Zn}^{+2}$ uptake seems to be promoted by lower ionic concentration in the culture solution as reported by Sela et al., (1989). Early seedling development of Z. mays appeared to be prone to the presence of small amounts of metals in the culture medium. The data support the assumption that metal sensitivity is probably due to strong tendency of this variety to accumulate heavy metals. This justifies that the corn variety 'Neelum' is not suitable for the cultivation under situations where water and soil suffer from occasional and/ or transitory metal pollution.

\section{Acknowledgement}

Thanks are due to ICI Pakistan Ltd, Multan, Pakistan for supplying corn seed variety Neelum for testing for heavy metals.

\section{References}

Barcelo J., Vazquez M. D. and Poschenrieder C., (1998).
Structural and ultra-structural disorders in cadmium treated bush bean plants (Phaseolus vulgaris L.). New Phytol. 108,37-49.

Becerril J. M., Munoz-Rueda A., Aparicio-Tejo P. and Gonzalez-Murua C., (1988). The effects of cadmium and lead on photosynthetic electron transport in clover and lucerne. New Phytol. 26, 357-363.

Chatterjee J. and Chatterjee C., (2000). Phytotoxicity of cobalt, chromium and copper in cauliflower. Environ. Pollut. 109, 69-74.

Claire L. C., Adriano D. C., Sajwan K. S., Abel S. L., Thomas D. P. and Driver J. T., Effects of selected trace metals on germinating seeds of six plant species. Water, Air and Soil Poll. 59, 231-240.

Ernst W.H.O., Phytotoxicity of heavy metals. In: C. Rodrigues-Barrueco (ed.), Fertilizers and environment. Kluwer Academic Publishers, Dordrechett, The Netherlands. Pages 423-430, 1996.

Fiussello N., (1973). Lead pollution: Effects on chlorophyll. Infor. Bot. 5, 107-108.

Leyval C., Singh V. B. R. and Joner E. J., (1995). Occurrence and infectivity of arbuscular mycorrhizal fungi in some Norwegian soils influenced by heavy metals and soil properties. Water, Air Soil Pollut. 84, 201-216.

Lindon F. C. and Henriques F. S., (1992). Copper toxicity in rice: Diagnostic criteria and effect on tissue Mn and Fe. Soil Sci., 154, 130-135.

Mullar D. H., Van Oort F. and Balbane M., (2000). Strategies of heavy metal uptake by three plant species growing near a metal smelter. Environ. Poll. 109, 231238.

Nishizono H., Kubta K. and Suzuki S., (1989). Accumulation of heavy metals in cell walls of Polygonum cuspidatum roots from metalliferous habitats. Plant. Cell. Physiol., 30, 595-598.

Scherbatskoy T., Klein R. M. and Badger G. J., (1987). Germination responses of forest tree seeds to acidity and metal ions. Environ. Exp. Bot. 27, 157-164.

Sela M, Garty J., and Tel-Or E., (1989). The accumulation and the effect of heavy metals on the water fern Azolla filiculoides. New Phytol. 112, 7-12.

Stefani A., Arduini I. and Onnis A., (1991). Juncus acutus: Germination and initial growth in presence of heavy metals. Ann. Bot. Fenn. 28, 37-43. 
Vojtechova M. and Leblova S., (1991). Uptake of lead and cadmium by maize seedlings and the effects of heavy metals on the activity of phosphoenol pyruvate carboxilase isolated from maize. Biol. Plant. 33: 386394.

Walley Y. A., Khan M. R. and Bradshaw A.D., (1974). The potential for evolution of heavy metals tolerance in plants .I. Copper and zinc tolerance in Agrostis tenuis. Heredity, 32: 309-319.

Welbaum G. E., Bradford K. J., Kyu-Ock Y., Booth D. T. and Oluoch M. O., (1998). Biophysical, physiological and biochemical processes regulating seed germination. Soil Sci. Res. 8: 161-172. 